\title{
FZD7 drives in vitro aggressiveness in Stem-A subtype of ovarian cancer via regulation of non-canonical Wnt/PCP pathway
}

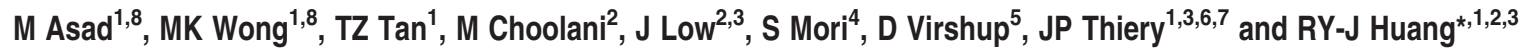

Ovarian cancer $(O C)$ can be classified into five biologically distinct molecular subgroups: epithelial-A (Epi-A), Epi-B, mesenchymal (Mes), Stem-A and Stem-B. Among them, Stem-A expresses genes relating to stemness and is correlated with poor clinical prognosis. In this study, we show that frizzled family receptor 7 (FZD7), a receptor for Wnt signalling, is overexpressed in the Stem-A subgroup. To elucidate the functional roles of FZD7, we used an RNA interference gene knockdown approach in three Stem-A cell lines: CH1, PA1 and OV-17R. Si-FZD7 OC cells showed reduced cell proliferation with an increase in the G0/G1 sub-population, with no effect on apoptosis. The cells also displayed a distinctive morphologic change by colony compaction to become more epithelial-like and polarised with smaller internuclear distances and increased z-axis height. Immunofluorescence (IF) staining patterns of pan-cadherin and $\beta$-catenin suggested an increase in cadherin-based cell-cell adhesion in si-FZD7 cells. We also observed a significant rearrangement in the actin cytoskeleton and an increase in tensile contractility in si-FZD7 OC cells, as evident by the loss of stress fibres and the redistribution of phospho-myosin light chain (pMLC) from the sites of cell-cell contacts to the periphery of cell colonies. Furthermore, there was reciprocal regulation of RhoA (Ras homolog family member A) and Rac1 (Ras-related C3 botulinum toxin substrate 1 (Rho family, small GTP-binding protein Rac1)) activities upon FZD7 knockdown, with a significant reduction in RhoA activity and a concomitant upregulation in Rac1 activity. These changes in PMLC and RhoA, as well as the increased TopFlash reporter activities in si-FZD7 cells, suggested involvement of the non-canonical Wnt/planar cell polarity (PCP) pathway. Selected PCP pathway genes (cadherin EGF LAG seven-pass G-type receptor 3 (CELSR3), prickle homolog 4 (Drosophila) (PRICKLE4), dishevelled-associated activator of morphogenesis 1 (DAAM1), profilin 2 (PFN2), protocadherin 9 (PCDH9), protocadherin $\alpha 1$ (PCDHA1), protocadherin $\beta 17$ pseudogene (PCDHB17), protocadherin $\beta 3$ (PCDHB3), sprouty homolog 1 (SPRY1) and protein tyrosine kinase 7 (PTK7)) were found to be more highly expressed in Stem-A than non Stem-A subgroup of OC. Taken together, our results suggest that FZD7 might drive aggressiveness in Stem-A OC by regulating cell proliferation, cell cycle progression, maintenance of the Mes phenotype and cell migration via casein kinase 1 1 -mediated non-canonical Wnt/PCP pathway.

Cell Death and Disease (2014) 5, e1346; doi:10.1038/cddis.2014.302; published online 17 July 2014

Ovarian cancer (OC) comprises vast heterogeneity, with multiple genetic and epigenetic aberrations, and can be robustly characterised into distinct subtypes based on its molecular characteristics. ${ }^{1-3}$ Each molecular subtype carries not only a specific molecular signature but also typically involves discrete signalling pathways. Despite this, the role of the Wnt pathway among the various OC subtypes remains undefined, partly because the Wnt signalling pathway has diverse mechanisms of activation in OC. Indeed, $\beta$-catenin mutation is mostly confined to endometrioid adenocarcinomas $^{4}$ where it is predominantly expressed in the nucleus, whereas, in serous and mucinous $\mathrm{OC}$, aberrant $\beta$-catenin expression is chiefly cytoplasmic. ${ }^{5}$ Aberrations in other Wnt pathway signalling components in OC have not been investigated in a subtype-specific manner.

Wnt signalling is broadly divided into canonical and noncanonical pathways. ${ }^{6}$ In canonical signalling, Wnt ligands bind to and activate the frizzled (FZD) receptors and low-density lipoprotein receptor-related protein5 or 6 (LRP5/6) coreceptor, which, in turn, inhibit the $\beta$-catenin destruction complex (APC, GSK3, casein kinase 1 (CK1) and axin). This stabilises $\beta$-catenin, which then translocates to the nucleus where it

${ }^{1}$ Cancer Science Institute of Singapore, Centre for Translational Medicine NUS Yong Loo Lin School of Medicine, Singapore, Singapore; ${ }^{2}$ Department of Obstetrics and Gynaecology, National University Hospital of Singapore, Singapore, Singapore; ${ }^{3}$ National University Cancer Institute of Singapore, Singapore, Singapore; ${ }^{4}$ Division of Cancer Genomics, Cancer Institute of Japanese Foundation for Cancer Research, 3-8-31 Ariake, Koto-Ku, Tokyo, Japan; ${ }^{5}$ Duke NUS Graduate Medical School, Singapore, Singapore; ${ }^{6}$ Department of Biochemistry, National University of Singapore, Singapore, Singapore and ${ }^{7}$ Institute of Molecular and Cell Biology, A*STAR, Singapore, Singapore

*Corresponding author: RY-J Huang, Cancer Science Institute of Singapore, NUS, Centre for Translational Medicine NUS Yong Loo Lin School of Medicine, 14 Medical Drive, Singapore 117599, Singapore. Tel: +65 6516 1148; Fax: +65 6779 4753; E-mail: ruby_yj_huang@nuhs.edu.sg

${ }^{8}$ These authors contributed equally to this work.

Abbreviations: OC, ovarian cancer; FZD7, frizzled family receptor 7; IF, immunofluorescence; pMLC, phospho-myosin light chain; CK1 1 , casein kinase 1 epsilon; PCP pathway, planar cell polarity pathway; RhoA, Ras homolog family member A; Rac1, Ras-related C3 botulinum toxin substrate 1 (Rho family, small GTP-binding protein Rac1)

Received 24.2.14; revised 27.5.14; accepted 09.6.14; Edited by Z-X Xiao 
interacts with T-cell factor/lymphoid enhancer factor-1 to promote the transcription of target genes crucial for cell proliferation, stem cell self-renewal ${ }^{7,8}$ and cellular differentiation. ${ }^{9}$ In the non-canonical Wnt/ $\mathrm{Ca}^{2+}$ pathway, the stimulation of $\mathrm{FZD}$ receptors in turn activates phospholipase $C$ via $G$ protein, which leads to an increase in the levels of intracellular $\mathrm{Ca}^{2+}$ and activates protein kinase $\mathrm{C}$, as well as the calcium/calmodulindependent kinase II. Deregulation of this non-canonical Wnt/ $\mathrm{Ca}^{2+}$ pathway has been implicated to drive cytoskeleton rearrangements, cellular motility, cellular proliferation and epithelial-mesenchymal (Mes) transition during cancer progression. ${ }^{10,11}$ In the non-canonical Wnt/planar cell polarity (PCP) pathway, Wnt ligand stimulates the activities of several small GTP-binding proteins, including RhoA (Ras homolog family member A), Rac1 (Ras-related C3 botulinum toxin substrate 1 (Rho family, small GTP-binding protein Rac1)) and cdc42, which regulate diverse processes, such as cytoskeleton rearrangement, cell polarity and migration. ${ }^{12,13}$ Aberrations in this Wnt/PCP pathway has been shown to cause the initiation and progression of malignant phenotypes through its stimulatory effect on cell proliferation, survival, abnormal tissue polarity, cell invasion and cancer metastasis. ${ }^{14,15}$

Among the 10 FZD receptors, frizzled family receptor 7 (FZD7) mediates both canonical and non-canonical Wnt signals. ${ }^{16,17} F Z D 7$ has been shown to activate canonical $\mathrm{Wnt} / \beta$-catenin signalling in breast, ${ }^{18}$ colorectal $^{19}$ and hepatocellular carcinoma (HCC), ${ }^{20}$ and its overexpression in colon cancer activates RhoA activity, suggesting a possible role for RhoA in non-canonical Wnt/PCP signalling. ${ }^{19}$ The enriched expression of FZD7 and other PCP proteins has also been found to regulate the interaction between chronic lymphoid leukaemia cells and their microenvironment. ${ }^{21}$ Despite these studies, there has still been no investigation into the role of FZD7 in OC. In the present study, we aimed to investigate the potential functional role of FZD7-mediated Wnt signalling in OC.

\section{Results}

FZD7 expression is enriched in Stem-A subtype of OC. We previously classified OC into five, biologically distinct subgroups - epithelial-A (Epi-A), Epi-B, Mes, Stem$A$ and Stem-B - based on their gene expression patterns. ${ }^{3}$ We investigated the expression level of FZD7 among these molecular subtypes as compared with our in silico OC microarray meta-analysis data sets. ${ }^{3}$ FZD7 expression was highest in the Mes (Mann-Whitney test, $P=6.17 \times 10^{-13}$ ) and Stem-A (Mann-Whitney test, $P=1.61 \times 10^{-8}$ ) molecular subtypes (Figure 1a), and this enrichment was further validated by QPCR in an independent OC collection, JPKO (GSE30311), with the mean FZD7 expression highest in Stem-A followed by Mes subtypes and lowest in Epi-A and Epi-B subtypes (Figure 1b). Although Mes and Stem-A subtypes confer poorer prognosis, the FZD7 expression was not significantly correlated with overall survival (data not shown). We next assessed FZD7 expression using an in vitro spheroid system, comprising a two-dimensional (2D) parental culture (SKOV3-P), a three-dimensional (3D) tertiary spheroid culture (SKOV3-S) and a 2D reattachment culture from tertiary spheroids (SKOV3-S2D) (Supplementary Figure 1A). We found a 9.38- and 16.98-fold increase in
FZD7 expression levels for SKOV3-S and SKOV3-S2D, respectively, as compared with the parental SKOV3 cells (Supplementary Figure 1B). We next utilised QPCR to examine comprehensively the expression levels of $F Z D 7$ in a panel of OC cell lines, SGOCL(43)-GSE28724. ${ }^{22}$ FZD7 expression was highest in an ovarian teratocarcinoma cell line, PA1, which harbours pluripotency and stem cell characteristics, followed by two ovarian adenocarcinoma lines, $\mathrm{CH} 1$ and OV17R, and then followed by SKOV3-S2D and SKOV3-S (Figure 1c). These results suggest that FZD7 expression was enriched significantly both in the Stem-A molecular subtype and in the SKOV3 spheroid system.

FZD7 has a role in OC cell proliferation and cell cycle progression. To examine the functional role of $F Z D 7$ in $O C$, two different FZD7 siRNAs (FZD7-5 and FZD7-6) and a negative control (non-targeted siRNA) were used to knockdown FZD7 in CH1, PA-1 and OV-17R cells. We achieved approximately $55-70 \%$ knockdown in $\mathrm{CH} 1, \mathrm{PA}-1$ and $\mathrm{OV}$ 17R (Figure 2a) as determined using QPCR. We first analysed the role of $F Z D 7$ on cell proliferation. Knockdown of FZD7 ( $\mathrm{CH} 1$ and PA1 after $48 \mathrm{~h}, \mathrm{OV} 17-\mathrm{R}$ cells after $72 \mathrm{~h})$ caused a significant decrease $(40 \%$ in $\mathrm{CH} 1$ and $\mathrm{PA} 1 ; 30 \%$ in OV17-R) in cell number and MTS readout as compared with the negative control (Figures $2 b$ and $c$ ). To ascertain whether the suppression in cell proliferation was due to cell cycle arrest or an increase in cell death/apoptosis, we performed a cell cycle analysis with Annexin $\mathrm{V}$ staining. We found that FZD7 knockdown increased the G0/G1 sub-population (Figure 3 and Supplementary Figure 3), whereas there was no significant difference in the fraction of Annexin V-positive apoptotic cells (Supplementary Figure 2) and $\beta$-galactosidase-positive cells (Supplementary Figure 3D). These data suggest that $F Z D 7$ knockdown suppressed cell proliferation by influencing cell cycle regulation without affecting apoptosis, indicating that FZD7 might have an important role in regulating the progression of the cell cycle in $\mathrm{OC}$.

FZD7 knockdown induces rearrangement of the actin cytoskeleton and cell-cell adhesion strengthening. In addition to the effect on cell proliferation, FZD7 knockdown cells showed significant phenotypic changes. Both $\mathrm{CH} 1-$ and PA1-FZD7-knockdown cells showed colony compaction that resembled a more epithelial-like morphology as compared with the dispersed fibroblastic morphology of the negative control cells as well as reduced internuclear distances (Figures $4 \mathrm{a}$ and b). OV-17R-FZD7-knockdown cells did not show obvious colony compaction morphologically. However, the internuclear distances in OV-17R-FZD7-knockdown cells were significantly reduced by $21 \%$ in $F Z D 7-5$ and $37 \%$ in FZD7-6 (Figure 4b). To further analyse the effect of FZD7 knockdown on colony compaction in these three cell lines, we labelled $\mathrm{F}$-actin with rhodamine-conjugated phalloidin (to observe the cytoskeletal changes) and performed immunofluorescence (IF) staining for $\beta$-catenin, p120-catenin and pan-cadherin (to localise adherens junctions (AJ) and cellcell junctions). The effect of FZD7 knockdown on colony compaction was evident by the decrease in the internuclear distance in DAPI-stained $\mathrm{CH} 1, \mathrm{PA} 1$ and OV17-R cells (Figure 5). FZD7-knockdown cells also showed reduced 


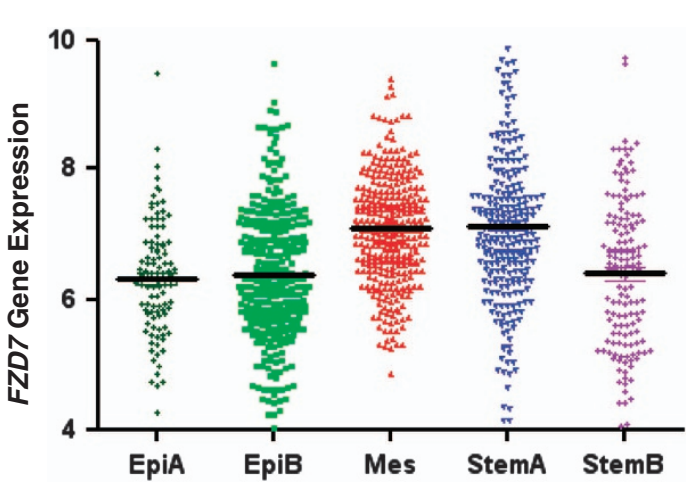

b

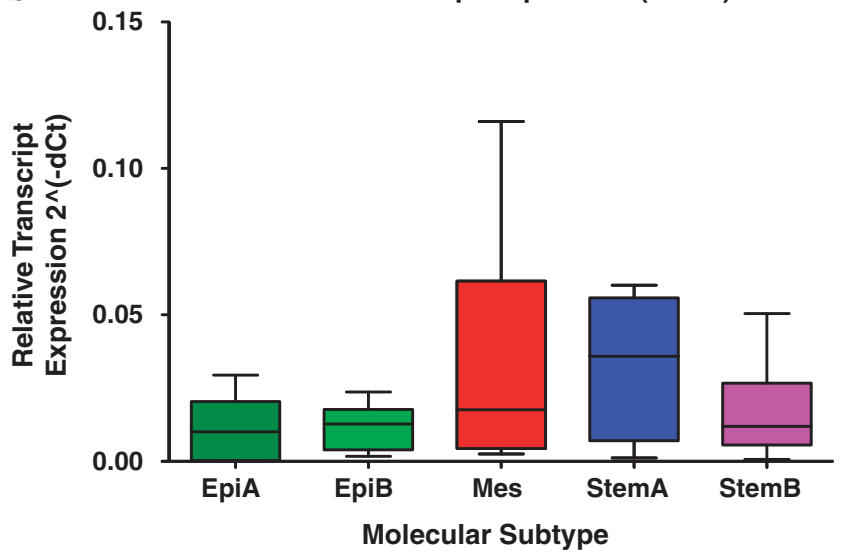

C

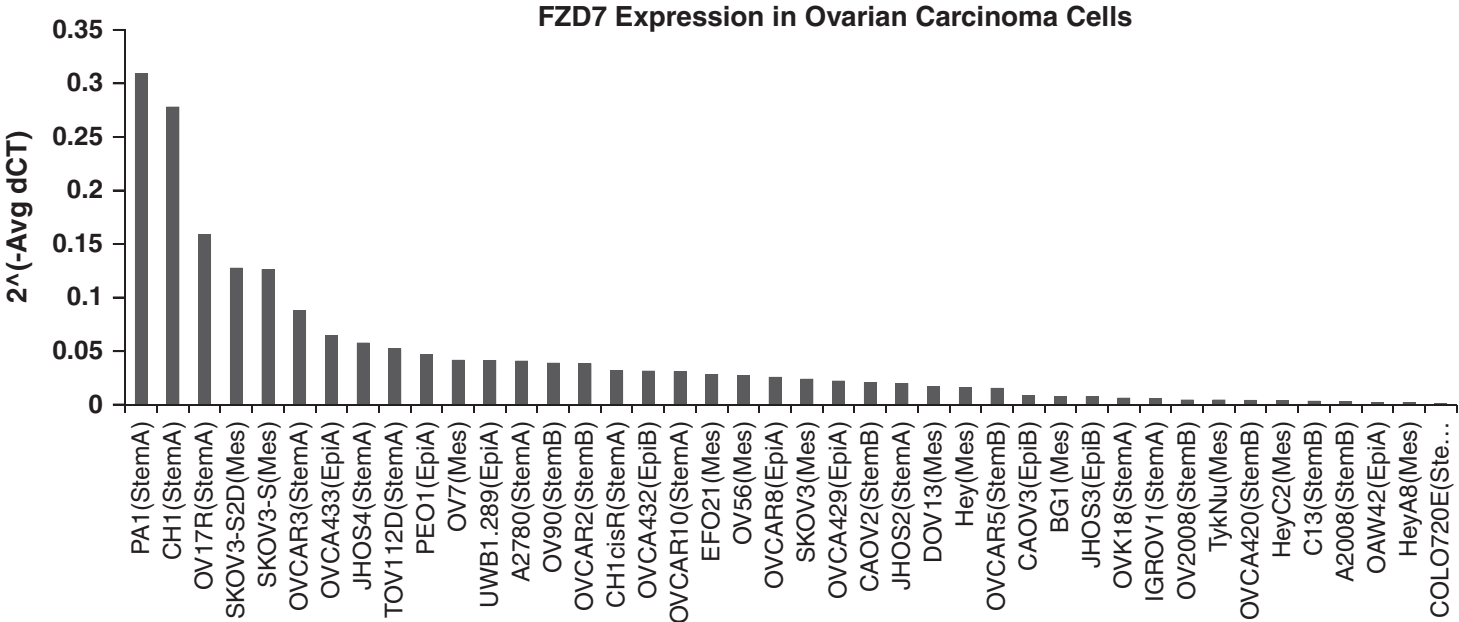

Figure 1 FZD7 expression was enriched in the Mes and Stem-A subtypes of ovarian cancer. (a) FZD7 gene expression data from 1538 ovarian tumour samples grouped into five, biologically distinct subgroups: Epi-A, Epi-B, Mes, Stem-A and Stem-B. (b) FZD7 transcript expression profile of patient tumour samples (JPKO collection) were assigned to the five subgroups. (c) FZD7 transcript expression levels in a panel of teratocarcinoma and OC cell lines (SGOCL(43))

stress fibre number and an altered distribution of the actin fibres along the cortical junctions in all three cell lines (Figure 5). Staining for $\beta$-catenin (Figures $5 \mathrm{a}$ and $\mathrm{b}$ ) and p120-catenin (Supplementary Figure 4) in $\mathrm{CH} 1$ and PA1 cells was increased in the linear junctions as compared with that observed in the negative control cells, with complete colocalisation of $\mathbf{F}$-actin and $\beta$-catenin in all three cell lines (Figure 5). We also observed an increased linear staining pattern for pan-cadherin, suggesting a strengthening of typeI cadherin-based cell-cell adhesion after FZD7 knockdown (Figure 6). These FZD7-knockdown cells also displayed more polarised cell morphology, as determined by measuring their maximal height along the $\mathrm{z}$ axis (Figure $7 \mathrm{c}$ and Supplementary Figure 5), with smaller internuclear distances as compared with that in the negative control. Taken together, FZD7 knockdown resulted in more polarised and compact colony formation that was associated with F-actin reorganisation away from stress fibres to cortical junctions and an increase in cadherin-based cell-cell adhesion.

FZD7 knockdown reciprocally inhibits $\mathrm{RhoA}$ and activates Rac1 activities, redistributes cellular tensile forces and decreases directional cell migration. The rearrangement of the actin cytoskeletal observed in FZD7-knockdown cells indicated changes in the activities of small GTPases. To confirm this hypothesis, we first performed GTPase G-LISA assays for small GTP-binding proteins that are known to be regulators of actin dynamics: RhoA, Rac1 and cdc42. In CH1, PA1 and OV-17R cells, FZD7 knockdown led to a significant reduction in RhoA activity (Figure 7a), but induced an upregulation in Rac1 activity (Figure 7b), with no significant change noted for cdc42 (Supplementary Figure 6).

We next conducted wound healing assays to examine the rate of migration of the cells following FZD7 knockdown. For negative control cells, the wounded areas were completely closed after $15 \mathrm{~h}(\mathrm{CH} 1$ and $\mathrm{PA}-1$ cells) and $32 \mathrm{~h}$ (OV-17R). In contrast, we found that two different siRNAs, FZD7-5 and FZD7-6, in the wound healing area were covered by $29 \%$ and $43 \%$ in $\mathrm{CH} 1,50 \%$ and $52 \%$ in $\mathrm{PA}-1,84 \%$ and $52 \%$ in OV-17R, respectively (Figure $7 d$ and Supplementary Figure 7).

Myosin light chain (MLC), a downstream target of RhoROCK, is known to regulate the assembly of actomyosin complexes and their contractility, particularly during collective cell migration. IF staining of the phosphorylated active form of 

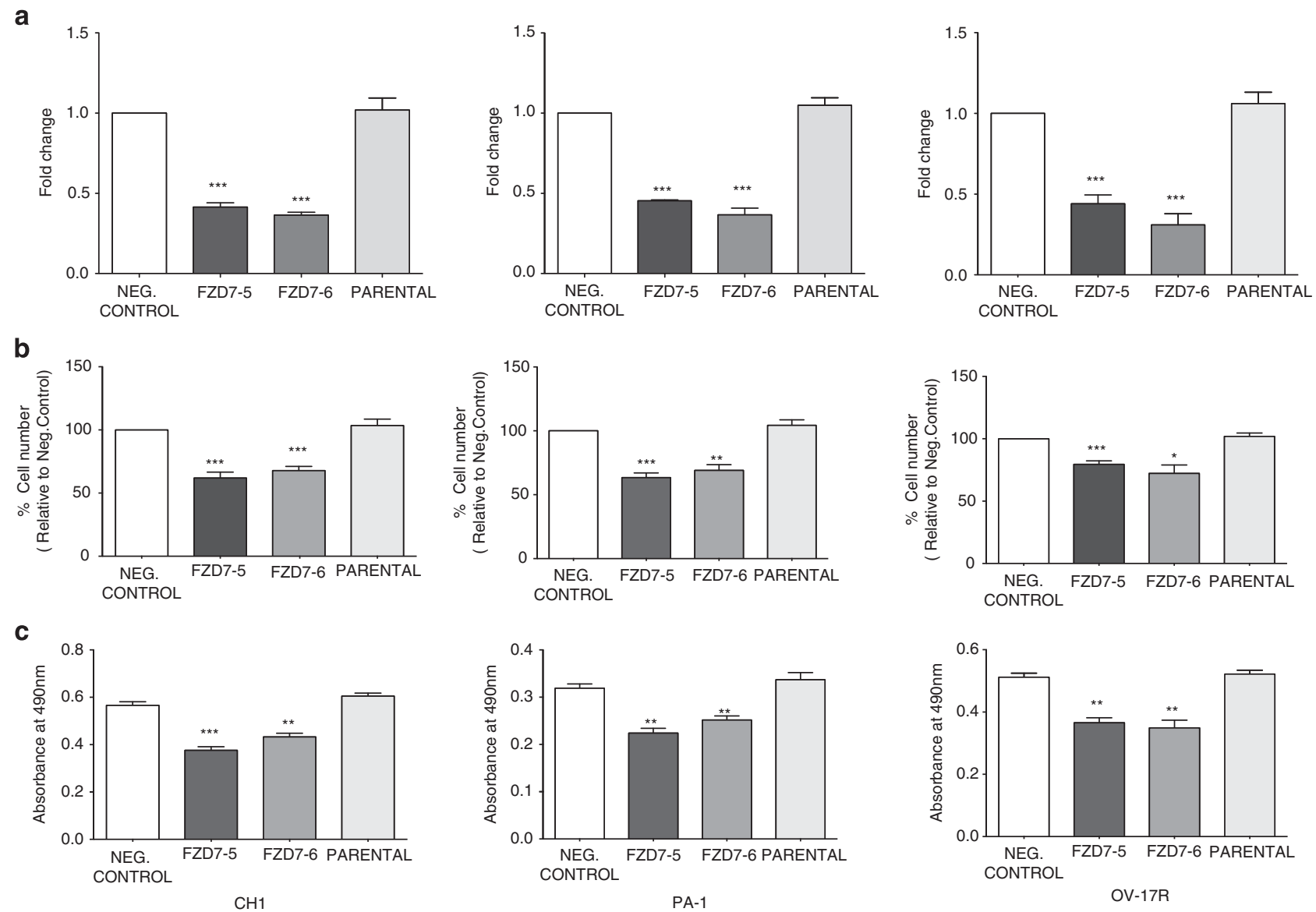

Figure 2 FZD7 downregulation decreases cell proliferation. (a) FZD7 expression (fold-change) after knockdown with two different siRNAs (FZD7-5 and FZD7-6), or the negative control (non-targeted) siRNA as compared with the untreated parental cells. (b) Cell counts after FZD7 siRNA transfection in CH1, PA-1 and OV-17R cell lines for the same treatment conditions described in (a). (c) MTS assay in CH1, PA-1 and OV-17R cell lines as described in (a). All experiments were performed as three independent experiments. $P$-value ${ }^{*}<0.05,{ }^{* *}<0.01$ and ${ }^{\star \star *}<0.001$
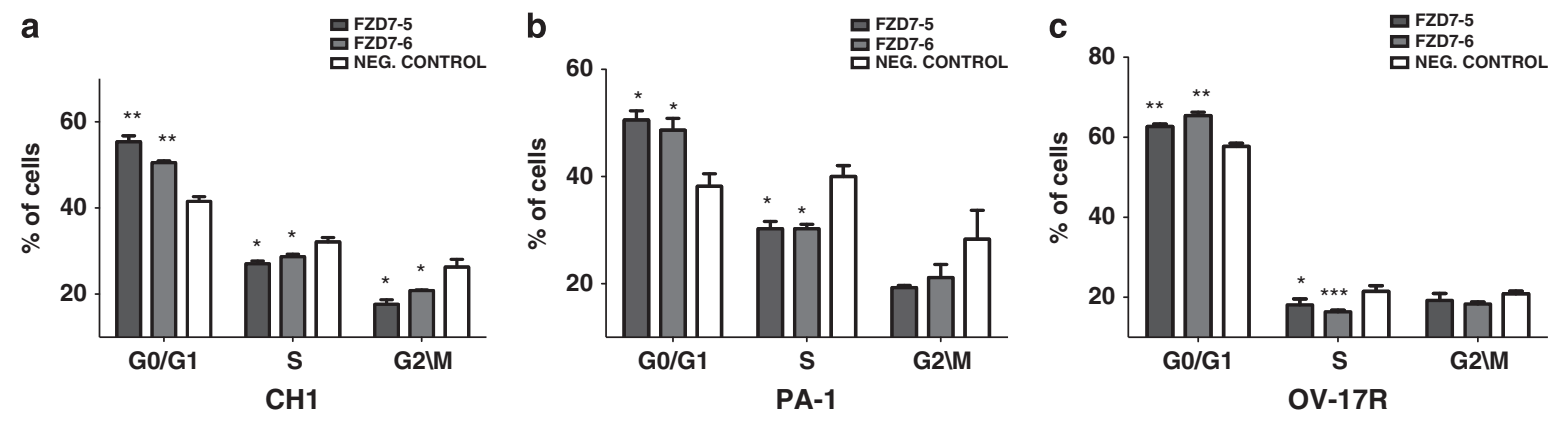

Figure 3 FZD7 downregulation reduces cell cycle progression. Cell cycle analysis in (a) $\mathrm{CH}$, (b) PA-1 and (c) OV-17R cell lines after FZD7 siRNA knockdown. P-value ${ }^{*}<0.05,{ }^{* *}<0.01$ and ${ }^{* * *}<0.001$

MLC, pMLC (S19), revealed that the knockdown of FZD7 caused PMLC to redistribute from intercellular contacts to the periphery of the colonies (Figure 8), suggesting a shift in the tensile force.

Taken together, these data suggest that FZD7 might have a role in regulating actin cytoskeleton rearrangement, cell migration and motility via the regulation of pMLC and Rho GTPases downstream effectors of non-canonical Wnt/PCP pathway.
FZD7 knockdown decreases CK1 $\varepsilon$ and DVL2 pSer143 localised at the centrosome. Our data prompted us to investigate further how FZD7 knockdown might affect other signalling components in the Wnt/PCP pathway. To further dissect the FZD7 downstream signalling events, we examined the IF staining patterns of $\mathrm{CK} 1 \varepsilon$, a downstream regulator of both canonical and non-canonical Wnt signalling pathways. ${ }^{23}$ In control cells, CK1 1 displayed cytoplasmic punctate dots in IF images under confocal microscopy (Supplementary 
a

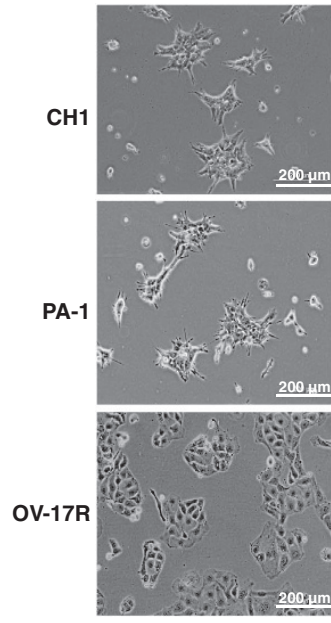

FZD7-5 SiRNA

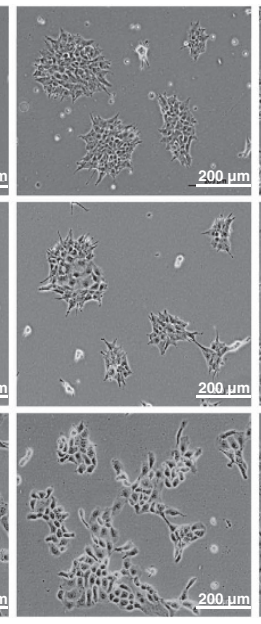

FZD7-6 siRNA

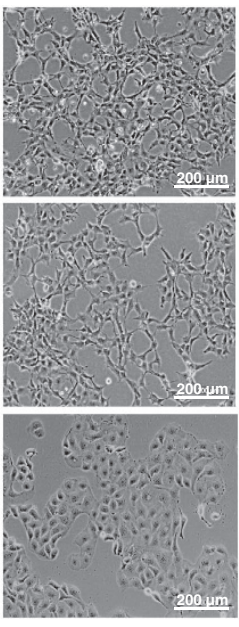

NEG.CONTROL

b
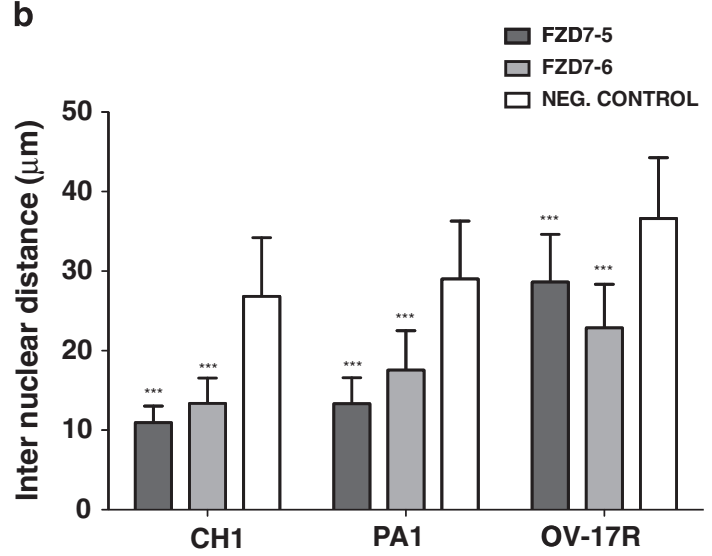

Figure 4 Knockdown of FZD7 induces phenotypic changes. (a) Phase-contrast images of $\mathrm{CH} 1, \mathrm{PA}-1$ and $\mathrm{OV}-17 \mathrm{R}$ cell lines. (b) Plots of the average internuclear distance of 200 nuclei after $F Z D 7$ knockdown. $P$-value ${ }^{\star * \star}<0.001$

Figure 8). However, some of the CK1 $1 \varepsilon$ signals colocalised with the $\gamma$-tubulin-positive centrosome, an organelle whose function is significantly influenced by Wnt signalling (Supplementary Figure 8). FZD7-knockdown cells, on the other hand, showed a significant reduction in $\mathrm{CK} 1 \varepsilon$ colocalisation with the $\gamma$-tubulin centrosome (Figure 9a). We also examined the IF staining patterns of serine 143-phosphorylated dishevelled 2 (DVL2) (DVL2 pSer143), which has a direct phosphorylation site for $\mathrm{CK} 1 \varepsilon .{ }^{24}$ Similar to the results of $\mathrm{CK} 1 \varepsilon$, the colocalisation of DVL2 pSer143 with centrosome ( $\gamma$-tubulin) was significantly decreased (Figure 9b) following FZD7 knockdown as compared with the control cells.

Interestingly, the knockdown of FZD7 induced a significant increase of TopFlash activity, which acts as an indicator for increased canonical Wnt signalling (Figure 9c). However, we did not observe any nuclear $\beta$-catenin translocation following FZD7 knockdown (Figure 5). Therefore, we speculate that FZD7 could be more biased towards non-canonical Wnt signalling and the increase in TopFlash activity upon FZD7 knockdown representative of the relative decrease in the noncanonical Wnt activity. However, this might be mediated in a ligand-independent manner that was suggested by the lack of phenotypic rescue by the non-canonical Wnt ligand, Wnt5a, in the FZD7-knockdown cells (Supplementary Figure 9).

A subset of Wnt/PCP pathway genes are highly expressed in Stem-A OC tumours and cell lines. Finally, we explored our OC microarray meta-analysis data set $^{3}$ to identify whether a subset of Wnt/PCP pathway genes other than FZD7 were also enriched in the Stem-A subtype. We divided the known Wnt/PCP genes into four categories: PCP upstream components, PCP core components, PCP downstream effectors and PCP modulators. ${ }^{25}$ As shown in Figure 9d, two core components (cadherin EGF LAG seven-pass G-type receptor 3 (CELSR3), prickle homolog 4 (Drosophila) (PRICKLE4)), two downstream effectors (DVL-associated activator of morphogenesis (DAAM1), profilin 2 (PFN2)) and six modulators (protocadherin 9 $(P C D H 9)$, protocadherin $\alpha 1$ (PCDHA1), protocadherin $\beta 17$ pseudogene (PCDHB17), protocadherin $\beta 3$ (PCDHB3), sprouty homolog 1 (SPRY1) and protein tyrosine kinase 7 (PTK7)) were significantly upregulated in both Stem-A tumours and cell lines. None of the upstream components showed a significant increase in this analysis.

\section{Discussion}

First identified to be overexpressed in oesophageal carcinoma, ${ }^{26}$ and later in gastric cancer, ${ }^{27}$ FZD7 is now known to be overexpressed and correlated with aggressive phenotypes in multiple human solid tumours. Studies have demonstrated FZD7 overexpression in $90 \%$ of HCCs and are shown to be correlated with increased cell motility and activation of Wnt pathway in HCC cell lines. ${ }^{28,29}$ In colorectal carcinoma (CRC) cell line model, FZD7 was shown to dictate morphologic transition and tumour growth, ${ }^{30}$ and FZD7 expression was found to be decreased at the invasive front of CRC, an area regarded as a site of dedifferentiation. ${ }^{31} \mathrm{CRC}$ patients with elevated levels of FZD7 are linked with shorter overall survival. ${ }^{19}$ However, to date, there is no existing literature on the role of $F Z D 7$ in OC.

In this report, we demonstrate that FZD7 is highly expressed in the Mes and Stem-A molecular subtypes of OC. These results are in line with previous findings suggesting that $F Z D 7$ regulates pluripotency and self-renewal, ${ }^{32,33}$ as the Stem-A subtype is typified by genes and pathways regulating stemness and de-differentiation. ${ }^{3}$ Furthermore, a metaanalysis of expression microarrays identified the marked upregulation of FZD7 in hESCs and its elevated expression in embryonal carcinoma and yolk sac carcinoma samples. ${ }^{34}$ The preferential FZD7 expression in normal stem cells and malignant embryonic cells suggests that $F Z D 7$ may have a major role in these pluripotent cell types. The differential expression of FZD7 in hESCs and human embryonic carcinoma cells has been further validated by plasma membrane proteomics, ${ }^{35}$ with results indicating that $F Z D 7$ is a novel ES cell-specific surface antigen. In addition to its roles in pluripotency and self-renewal, FZD7 has been shown to have a role in mediating the exit of hESCs from a pluripotent state and their entry towards mesoderm specification induced by non-canonical Wnt signalling. ${ }^{36} F Z D 7$ is also found to be 
a

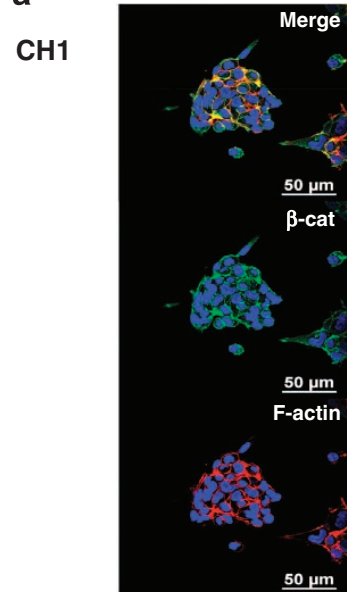

FZD7-5 siRNA

\section{b}

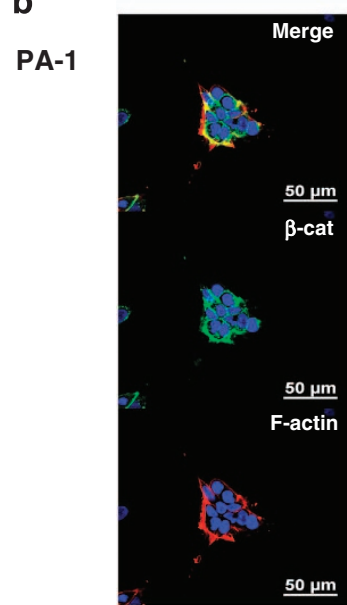

FZD7-5 SIRNA

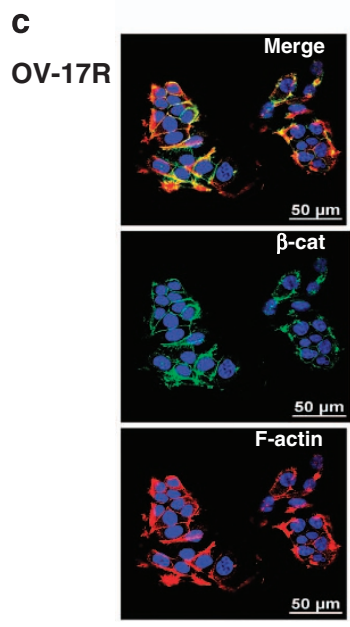

FZD7-5 siRNA

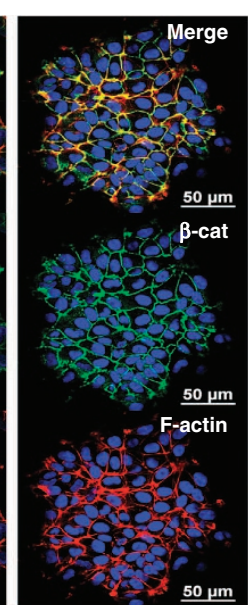

FZD7-6 siRNA

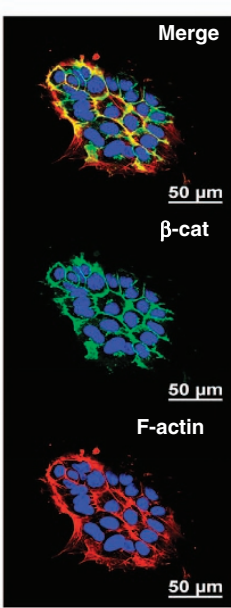

FZD7-6 siRNA

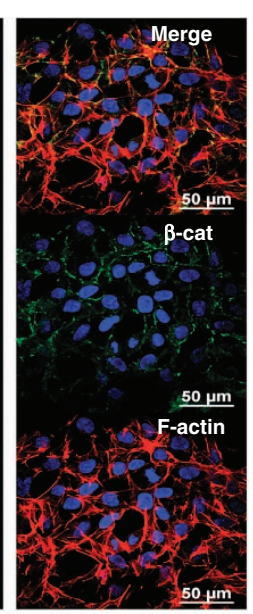

NEG. CONTROL

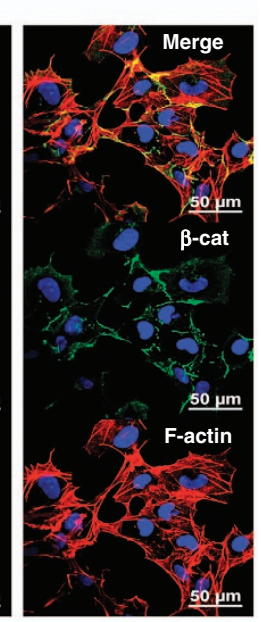

NEG. CONTROL

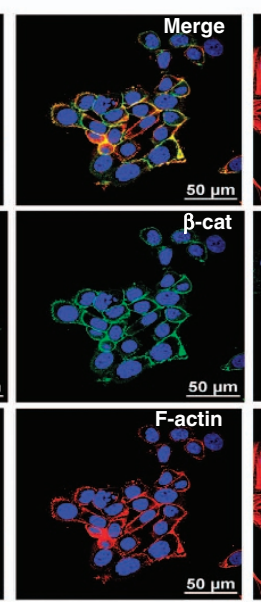

FZD7-6 siRNA

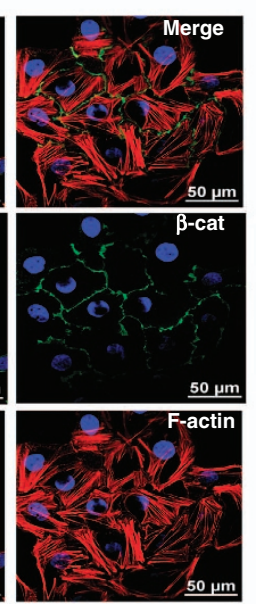

NEG. CONTROL

Figure 5 FZD7 knockdown induces phenotypic changes by rearrangement of actin cytoskeleton and strengthening of cell-cell adhesion. IF staining for $\beta$-catenin and F-actin in (a) $\mathrm{CH} 1$, (b) PA-1 and (c) OV-17R cell lines, respectively, after transfection with the negative control, FZD7-6 or FZD7-5 siRNA

differentially expressed in the satellite stem cells in skeletal muscles. ${ }^{37}$ Collectively, this evidence indicates that FZD7 is ubiquitously expressed in pluripotent stem cells and has a role in cell fate determination, and suggests the intriguing possibility that FZD7 might have an important role as a novel molecular driver for stem cell properties in OC.

We show here that FZD7 downregulation in Stem-A OC cells reduces cell proliferation by increasing the proportion of cells in the G0/G1 phase. This is consistent with the findings in triple-negative breast cancer ${ }^{18}$ and in $\mathrm{CRC}^{19}$ where downregulation of FZD7 decreases cell proliferation. However, cell cycle regulation mechanisms might involve both canonical and non-canonical Wnt pathway activation. In breast cancer, ${ }^{18}$ FZD7 knockdown downregulates cyclin D1 and c-myc, both of which are known to control cell cycle progression and are canonical Wnt pathway target genes. In $\mathrm{CRC},{ }^{19}$ the loss of $F Z D 7$ decreases JNK and c-jun activities, two downstream targets in the non-canonical Wnt/PCPRhoA pathway. RhoA activation is also shown to drive cell proliferation and invasion in MDA-MB-231 breast cancer cells $^{38}$ and regulates the G1-to-S progression of cells in the cell cycle in gastric cancer by modulating INK4 family members. $^{39}$

In an in vitro CRC morphogenesis culture system, FZD7 was demonstrated to be necessary for Mes-epithelial transition (MET) of the monolayer (Mes state) into the 3D spheres (epithelial state). ${ }^{40}$ In this model, the loss of FZD7 affects this transition and maintained cells in a Mes state in the monolayer without the ability to form the more epithelial 'carcinoids'. This is in line with our finding that FZD7 expression is upregulated in the SKOV3S cultures compared with monolayers of SKOV3P. However, it would be somewhat misleading to suggest that $F Z D 7$ is crucial in driving MET, as the inability to generate $3 \mathrm{D}$ carcinoids following the loss of FZD7 could simply suggest that FZD7 is also important in anchorageindependent growth. FZD7 seems to be functionally important for overcoming anoikis resistance. OCs lacking FZD7 are more prone to undergoing anoikis in suspension cultures, which, in turn, leads to a reduction in spheroid formation (unpublished data). More intriguingly, OC cells lacking FZD7 seem to display a more epithelial and polarised phenotype, evident by the increased colony compaction, the decreased number of stress fibres, the decreased internuclear distance and the increased z-axis height. Therefore, contrary to what has been suggested for the $\mathrm{CRC}$ in vitro morphogenic culture systems, FZD7 might be an important regulator for maintaining the Mes state in OC. This is also demonstrated by the $F Z D 7$ expression pattern in OC; FZD7 is highly expressed in the Mes molecular subtype, which is believed to have undergone epithelial-Mes transition.

One plausible mechanism of how FZD7 regulates the Mes state is via the Wnt/PCP signalling pathway and the activity of the small GTPases. Our result shows that knockdown of FZD7 suppresses RhoA but upregulates Rac1. RhoA and Rac1 activities have been shown to have inverse relationship that would dictate the epithelial-Mes states of cells. Activation of Rac1 by Tiam1 downregulates RhoA in NIH3T3 fibroblasts and induces strengthening of cadherin-based cell-cell adhesion, with transformation of cells to an epithelial-like morphology with suppressed cell migration capabilities. ${ }^{41}$ Inversely, 

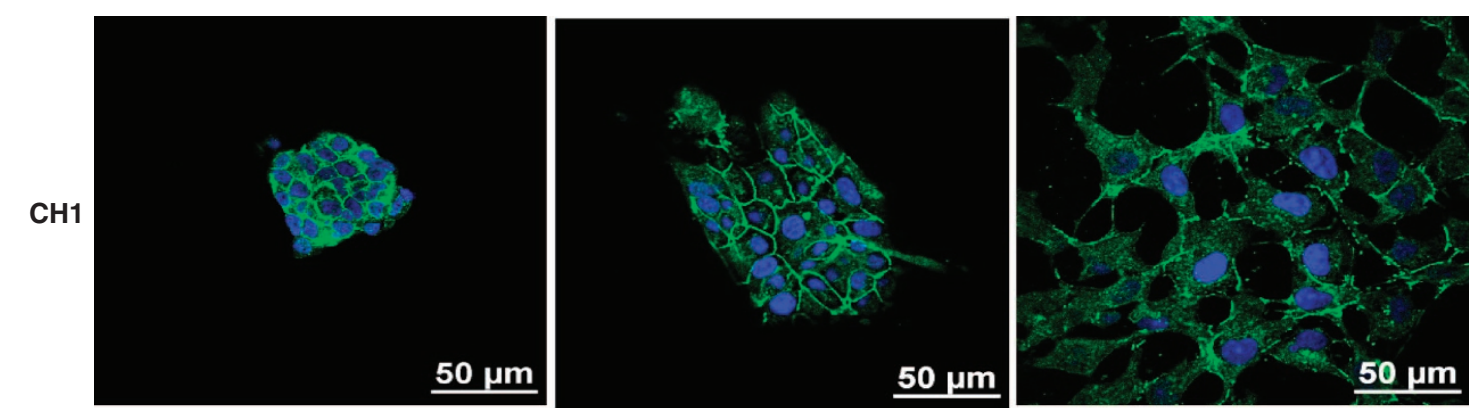

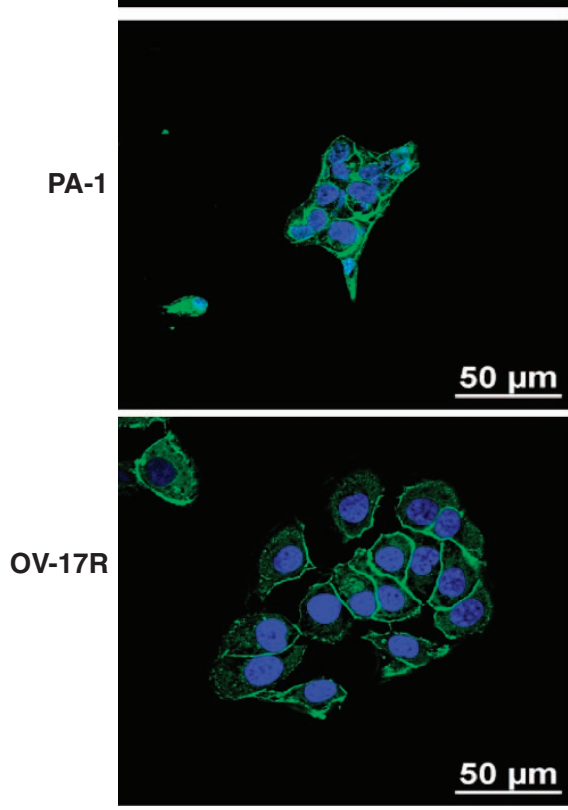

FZD7-5 siRNA

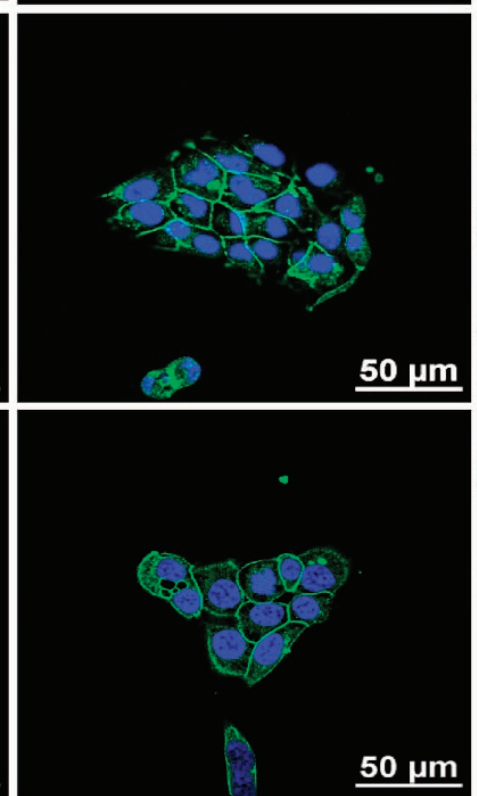

FZD7-6 siRNA

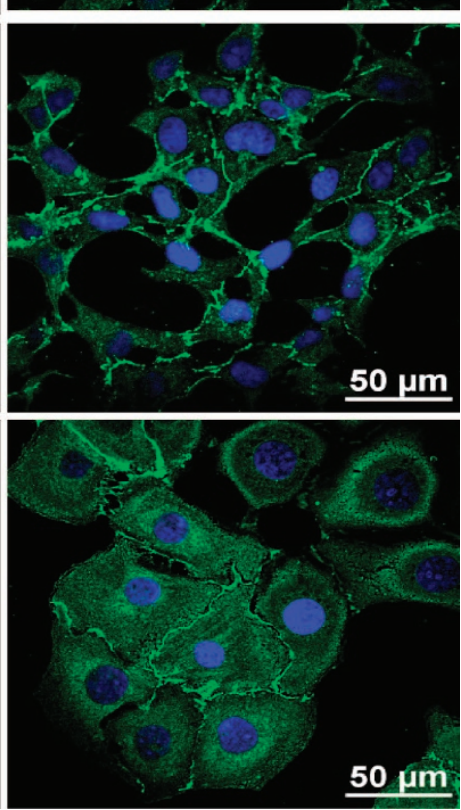

NEG. CONTROL

Figure 6 FZD7 downregulation strengthens cadherin-based cell-cell adhesion. IF staining for pan-cadherin in CH1, PA-1 and OV-17R cell lines after FZD7 knockdown

activation of RhoA induces migratory and fibroblastic phenotype in NIH3T3 fibroblasts. In MDCK cells, dominant-active mutants of Rac1 results in increased $\mathrm{E}$-cadherin, $\beta$-catenin and other adherens junctional proteins at cell-cell contacts. ${ }^{42}$ In pancreatic cancer cells, Rac1 and RhoA activities also show a reciprocal regulation, ${ }^{43}$ where Rac1 activation induces an epithelial phenotype with an increase in cadherin-based cell-cell adhesion at cell-cell junctions, whereas RhoA induces a Mes phenotype with a migratory behaviour, ${ }^{43}$ consistent with the works of others. ${ }^{41}$ Accordingly, our woundhealing assay demonstrated a decrease in cell migration after FZD7 knockdown. The activation of RhoA is an important downstream effect in the non-canonical Wnt/PCP pathway to regulate cell motility, cellular invasion and migration. This has been documented by the overexpression of FZD7 in CRC, ${ }^{19}$ and its activation by Wnt5a in gastric cancer, ${ }^{44}$ breast cancer ${ }^{45}$ and in melanoma. ${ }^{46}$ Finally, the phosphorylation of $\mathrm{MLC}^{47}$ is an important event to regulate kinase assembly of actomyosin complexes and their contractility during collective migration. ${ }^{48}$ After FZD7 knockdown, pMLC (S19) redistributes from intercellular contacts to the periphery of cell colonies. This not only suggests a temporal shift in the actomyosin contractility among cells but also indicates a change in the downstream activities of proteins along the
Rho-ROCK axis. Therefore, regulation of the reciprocal changes in RhoA and Rac1 activities might be an important tool in managing the FZD7/PCP pathway in OC. However, our study could not exclude the contribution of $\mathrm{Wnt} / \mathrm{Ca}+$ pathway, which is critical in the regulation of cytoskeleton changes and metastsis. ${ }^{10}$

The FZD7/PCP pathway may also contribute to the maintenance of the Mes phenotype by regulating cadherinbased cell-cell adhesion. We demonstrated the increased linear junctional staining of pan-cadherin, $\beta$-catenin and $\mathrm{p} 120$ catenin at cell contacts after FZD7 knockdown, suggesting a role for FZD7 in cadherin-based cell-cell adhesion at cell junctions. This is corroborated by the findings of others, where FZD7has been shown to interact physically with C-cadherin in Xenopus and the FZD7-cadherin complex prevents cisdimerisation and lateral clustering of C-cadherin. ${ }^{49}$ Lateral clustering of cadherins is thought to enforce adhesion strength by biochemical, biophysical and theoretical approaches. $^{50,51}$ Thus, depleting FZD7 in Stem-A OC cells might free up type-I cadherin ( $\mathrm{N}$-cadherin in this case) and enhance its lateral clustering and to contribute to a more polarised and epithelial phenotype. Interestingly, FZD7 signalling does not reduce cell adhesion by inducing C-cadherin internalisation, ${ }^{49}$ which is a common mechanism 
a
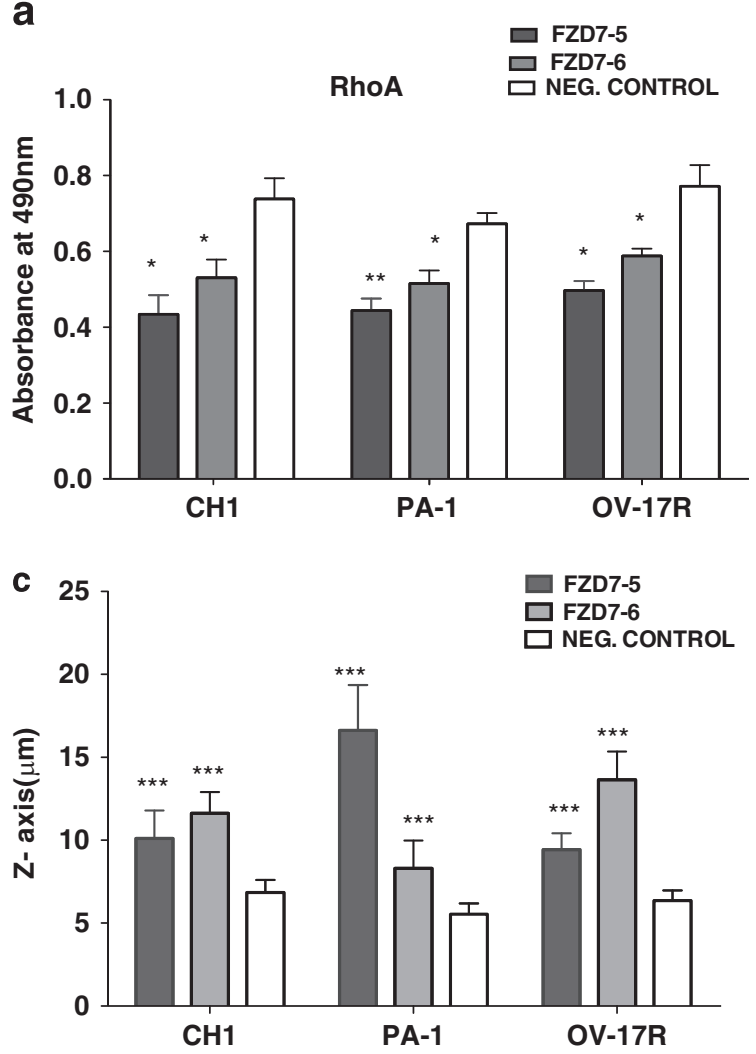

b
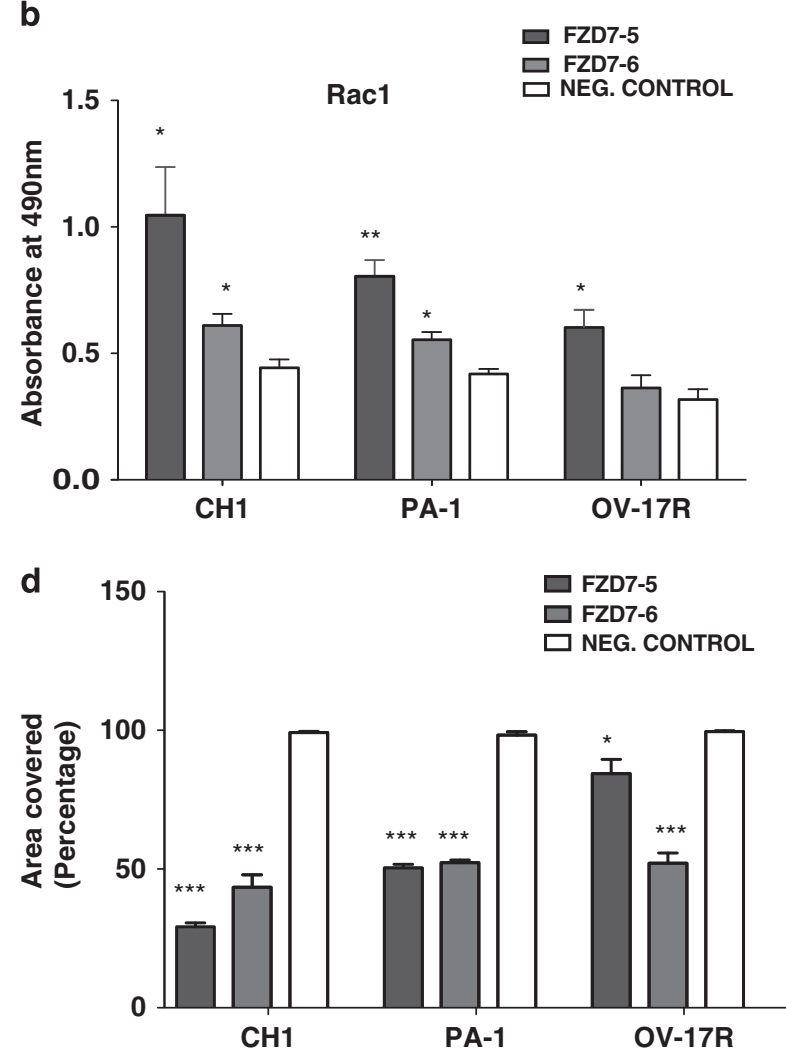

Figure 7 FZD7 downregulation inhibits RhoA but activates Rac1 activity. (a) G-LISA RhoA and (b) Rac1 expression after FZD7 downregulation in CH1, PA-1 and OV-17R cell lines. (c) Graph shows cell polarity (in $\mu \mathrm{M}$ ) (z axis) after knockdown with FZD7 siRNA. (d) Graph shows the results of the wound healing assay after knockdown of $F Z D 7$. $P$-value ${ }^{*}<0.05,{ }^{* *}<0.01$ and ${ }^{* *}<0.001$

resulting in the endocytosis of cadherin complexes during cell migration. ${ }^{52}$ It is believed that, during this internalisation process, $\beta$-catenin may decouple from the cadherin complex and translocate into the nucleus to initiate canonical Wnt signalling. ${ }^{53}$ As we did not detect any nuclear localisation of $\beta$-catenin in Stem-A OCs, the contribution and implications of this increased canonical $\beta$-catenin activity following FZD7 knockdown is still unclear.

$\mathrm{CK} 1 \varepsilon$ may also be a key signalling molecule mediating noncanonical PCP signals downstream of $F Z D 7$. CK $1 \varepsilon$ belongs to a serine-threonine kinase family and regulates Wnt signalling in dual manner: CK1 positively regulates $\beta$-catenin ${ }^{54}$ by destabilising the $\beta$-catenin destruction complex, and also negatively regulates Wnt signalling by axin-mediated phosphorylation of $\beta$-catenin at $\mathrm{S} 45 .{ }^{55}$ In breast cancer, a CK1 $1 \varepsilon$ mutation was shown to inhibit canonical $\mathrm{Wnt} / \beta$-catenin signalling and activate the non-canonical Wnt/PCP pathway that regulates cell migration. ${ }^{56} \mathrm{CK} 1$ also phosphorylates DVL and regulates its downstream functions. ${ }^{57}$ We found decreased localisation of CK1 $\varepsilon$ and phosphorylated DVL2 (Ser143) at the signalling triaging centre centrosome after FZD7 knockdown in Stem-A OC cells. This coupling of CK1\& and PDVL2 at the centrosome has been suggested to regulate the disassembly of primary cilia during early cell cycle progression. ${ }^{24}$ Thus, their decoupling could explain the increase in the proportion of G0/G1-phase cells in our FZD7-knockdown Stem-A OC cells. In addition, CK1 1 has been reported to promote cell proliferation and survival in $\mathrm{OC}$ and $\mathrm{OC}$ tumours with high $\mathrm{CK} 1 \varepsilon$ protein expression are correlated with poorer patient survival. ${ }^{58}$

In conclusion, our data indicate an elevation in FZD7 and its related PCP pathway genes in the Stem-A subgroup of $O C$. FZD7 might drive aggressiveness in Stem-A OC by regulating cell proliferation, cell cycle progression, maintenance of the Mes phenotype and cell migration via a CK1 1 -mediated, noncanonical Wnt/PCP pathway. Blocking the FZD7/PCP pathway has been suggested to be achievable by small molecular inhibitors to $F Z D 7,{ }^{59}$ or the use of an $F Z D 7$-specific fragment antigen-binding molecule, ${ }^{33}$ or through the use of antibodyinduced cytotoxicity. ${ }^{60}$ Therefore, OC patients with Stem-A molecular subtype or tumours with evidence of activity in the FZD7-mediated non-canonical PCP signalling would potentially benefit from these FZD7-guided therapies.

\section{Materials and Methods}

Quantitative real-time PCR of FZD7 on SGOCL(43) and JPKO collection. Cell lines were acquired from various sources. CAOV3, OV90, OVCAR3, SKOV3, TOV112D and UWB1.289 were purchased from ATCC (American Type Tissue Culture Collection, Manassas, VA, USA). PEO1 and PEO4 were gifts from the Clare Hall Laboratories (Cancer Research UK, Hertfordshire, UK). EFO21 was purchased from DSMZ (Deutsche Sammlung von Mikroorganismen und Zullkulturen GmbH, Braunschweig, Germany). A2780, COLO720E, OAW28, OAW42, OV7, OV17R and OV56 were purchased from ECACC (European Collection of Cell Cultures, Salisbury, UK). OVK18 was purchased from the RIKEN Cell Bank (RIKEN BioResource Center Cell Bank, Ibaraki, Japan). All other $\mathrm{OC}$ and teratocarcinoma cell lines not mentioned above, together with all patient tumour samples, were acquired from the repository of Dr. Noriomi 

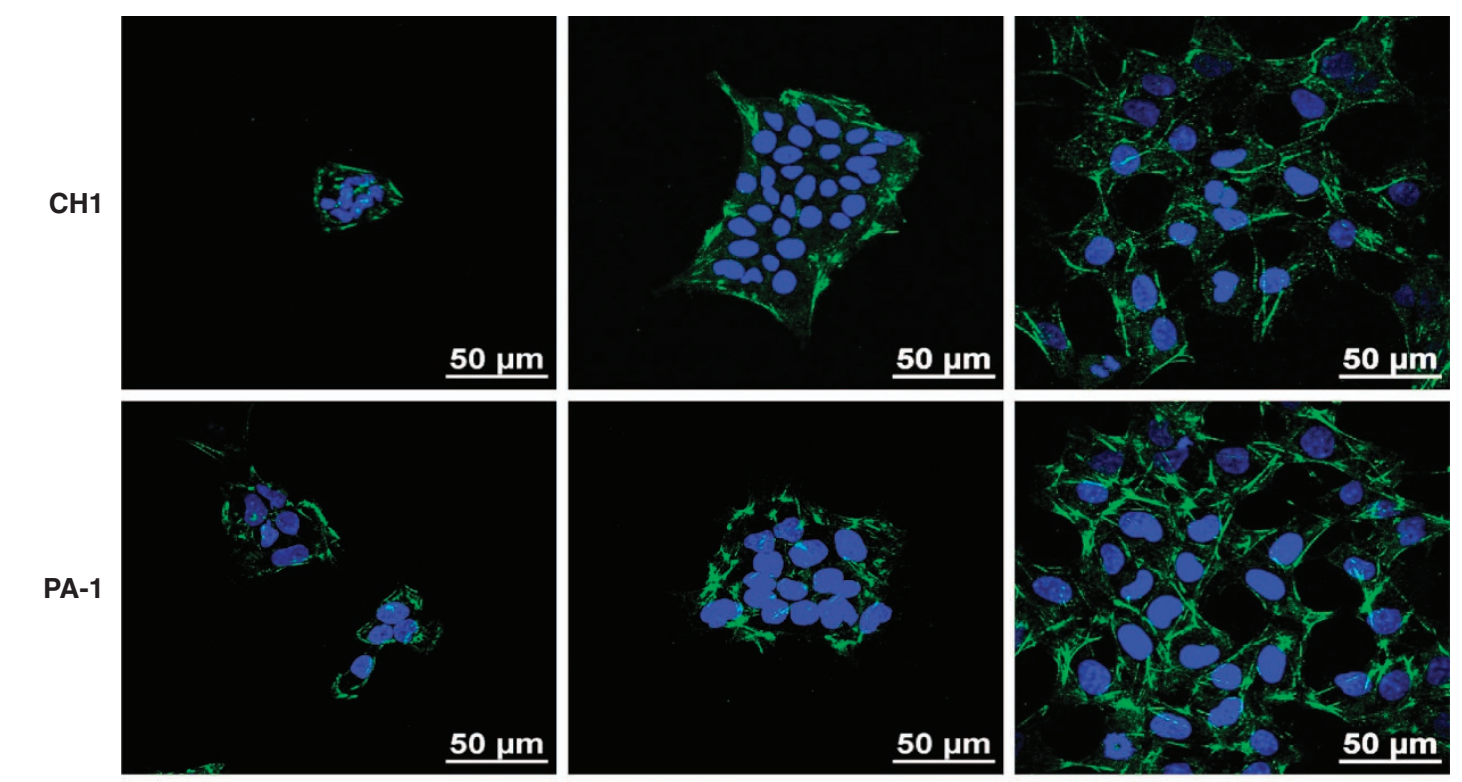

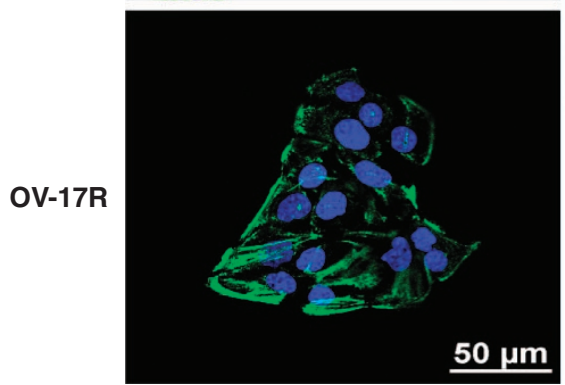

FZD7-5 siRNA

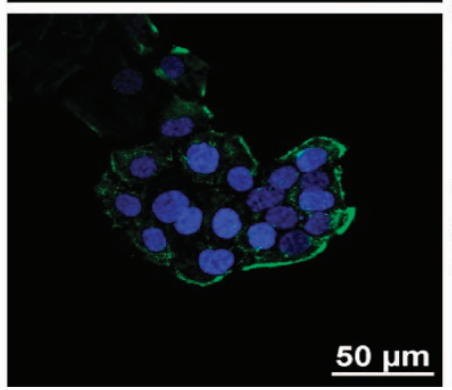

FZD7-6 siRNA

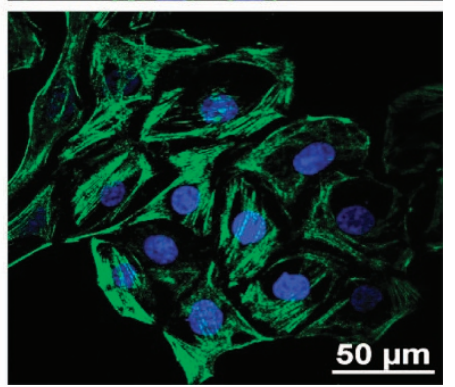

NEG. CONTROL

Figure 8 IF staining for phosphorylated MLC2 on Ser19 in (a) CH1, (b) PA-1 and (c) OV-17R cell lines, respectively, after FZD7 knockdown

Matsumura (Kyoto University, Kyoto, Japan). Cell lines and patient tumour samples were lysed in TRIzol (Life Technologies, Carlsbad, CA, USA) and the total/micro-RNA mixes were purified using miRNeasy spin columns (Qiagen, Valencia, CA, USA). CDNA were subsequently synthesised using the SABiosciences RT ${ }^{2}$ First Strand cDNA Kit (Qiagen). cDNA (200 ng) was mixed with the SABiosciences human FZD7 primer (PPH02420) and $2 \times$ SYBR Master Mix to a final volume of $25 \mu \mathrm{l}$ per reaction. The real-time reaction was carried out the using a standard run programme on the $7900 \mathrm{HT}$ Fast Real-Time PCR System (Applied Biosystems; Life Technologies Corp., Foster City, CA, USA). $\Delta C_{T}$ values were obtained by subtracting the average $C_{\mathrm{T}}$ values of five housekeeping genes (ACTB, B2M, GAPDH, HPRT1 and RPL13A; Qiagen SABiosciences, Frederick, $M D, U S A)$ from that of FZD7.

Cell cultures. Human $\mathrm{OC} \mathrm{CH} 1$ cell line was cultured in DMEM-Hi glucose (Nacalai Tesque, Kyoto, Japan) supplemented with 10\% FBS (Biowest, Nuaillé, France), $10 \mu \mathrm{g} / \mathrm{ml}$ insulin (Sigma, St. Louis, MO, USA), $0.5 \mu \mathrm{g} / \mathrm{ml}$ hydrocortisone (Sigma-Aldrich, St. Louis, MO, USA), 1\% penicillin and streptomycin (SigmaAldrich). The PA1 cell line was cultured in DMEM-Hi glucose supplemented with $10 \% \mathrm{FBS}$, and $1 \%$ of penicillin and streptomycin. The OV-17R cell line was cultured in DMEM-Hi glucose and Hams F12 (Nacalai Tesque) supplemented with $5 \% \mathrm{FBS}, 10 \mu \mathrm{g} / \mathrm{ml}$ insulin, $0.4 \mu \mathrm{g} / \mathrm{ml}$ hydrocortisone and $1 \%$ of penicillin and streptomycin.

FZD7 siRNA knockdown and real-time RT-PCR. FZD7 siRNA, a nontargeting negative control siRNA and HiPerFect Transfection Reagent were obtained from Qiagen. CH1, PA-1 and OV-17R cells were seeded in 6-well plates (Nunc, Roskilde, Denmark) and transfected with FZD7 siRNA (FZD7-5 and FZD7-6 having target sequence 5'-CAACGGCCTGATGTACTTTAA-3', 5'-ATGG GTTAATTTCCAGGGTCA-3', respectively) or negative control siRNA using HiPerFect, according to the manufacturer's protocol. FZD7 expression was quantified after $48 \mathrm{~h}$ (CH1, PA-1) or $72 \mathrm{~h}$ (OV-17R). Total RNA was isolated using an RNeasy Mini Kit (Qiagen) and the RNA was reverse transcribed using the $\mathrm{RT}^{2}$ First Strand Kit (Qiagen). Quantitative real-time PCR was performed using $\mathrm{RT}^{2}$ SYBR Green ROX qPCR Master Mix (Qiagen) and an ABI 7900HT (Applied Biosystems).

Cell cycle analysis. $\mathrm{CH} 1, \mathrm{PA}-1$ and $\mathrm{OV}-17 \mathrm{R}$ cells were synchronised by serum starvation, seeded into 6 -well plates and then transfected with two different FZD7 siRNA sequences - FZD7-5 or FZD7-6 (Qiagen) - or the non-targeting negative control siRNA. After $48 \mathrm{~h}(\mathrm{CH} 1, \mathrm{PA}-1)$ or $72 \mathrm{~h}(\mathrm{OV}-17 \mathrm{R})$, the cells were harvested, washed with ice-cold PBS and fixed with ice-cold $70 \%$ ethanol overnight at $4{ }^{\circ} \mathrm{C}$. The cells were then centrifuged at $600 \times g$ for $10 \mathrm{~min}$ at $4{ }^{\circ} \mathrm{C}$, and the ethanol discarded. The cells were washed two times with ice-cold PBS. The cells were then counted and equal numbers of cells from each condition were transferred into 5-ml round tubes. The cells were treated with $10 \mu \mathrm{g} / \mathrm{ml}$ RNase A (Roche Applied Science, Mannheim, Germany) for $10 \mathrm{~min}$ at room temperature and then stained with $200 \mathrm{ng} / \mathrm{ml}$ of propidium iodide (Sigma-Aldrich) in the dark for $15 \mathrm{~min}$. Cell cycle analysis was performed using BD LSR II (BD Biosciences, Franklin Lakes, NJ, USA) and analysed using the FlowJo flow cytometry analysis software (Tree Star Inc., Ashland, OR, USA).

IF staining. The cells were grown on glass coverslips in 6 -well plates and then transfected with one of two FZD7 siRNA sequences (FZD7-5 and FZD7-6) or the non-targeting negative control siRNA for $48 \mathrm{~h}$. For staining of F-actin, $\beta$-catenin, p120 catenin and pMLC (Ser19), the transfected cells were washed two times with PBS to remove residual media/serum, fixed with $4 \%$ paraformaldehyde for $10 \mathrm{~min}$ at room temperature and then permeabilised with $0.05 \%$ Triton $X-100$ for 5 min at room temperature. For CK1E, DVL2 pSer143 and pan-cadherin staining, the cells were washed two times with PBS and fixed with ice-cold methanol for $10 \mathrm{~min}$ at $-20^{\circ} \mathrm{C}$. Primary antibodies were used at the following concentrations: $1: 100$ for 
a

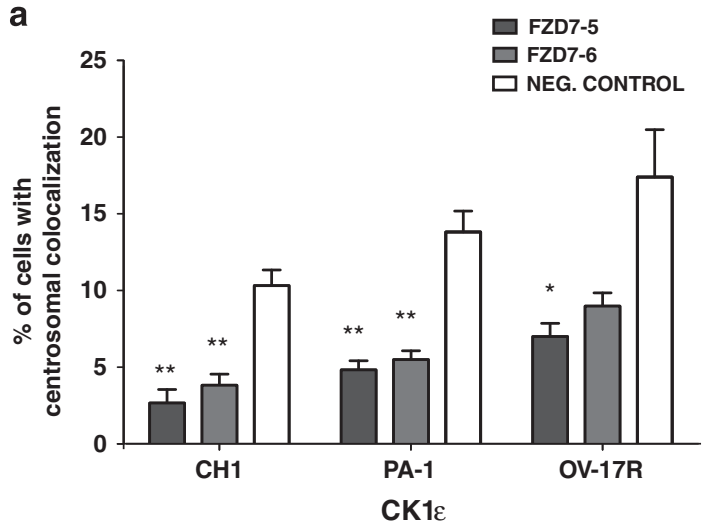

C

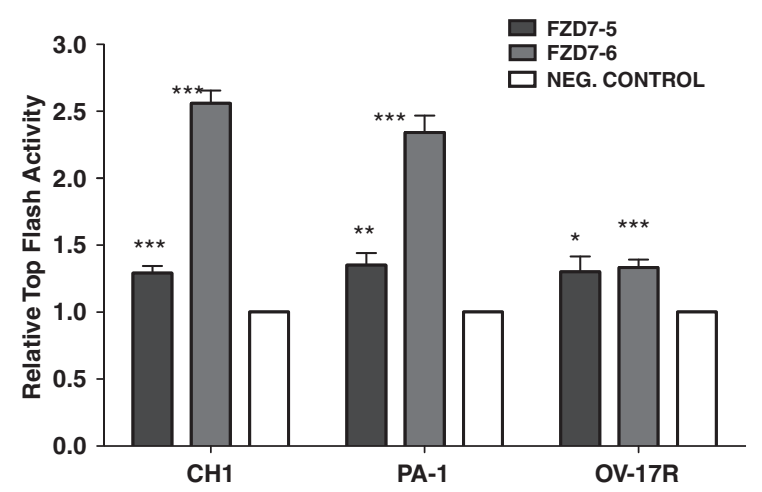

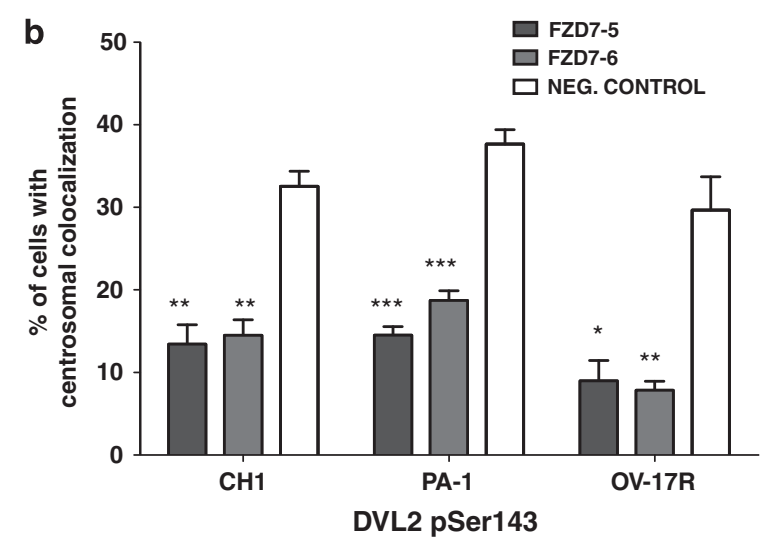

d

\begin{tabular}{|c|l|l|l|}
\hline & Gene IDs & $\begin{array}{l}\text { Mann Whitney } \\
\text { p-value (tumor) }\end{array}$ & $\begin{array}{l}\text { Mann Whitney } \\
\text { p-value (cell } \\
\text { line) }\end{array}$ \\
\hline \multirow{2}{*}{$\begin{array}{c}\text { PCP Core } \\
\text { Component }\end{array}$} & CELSR3 & $2.33 \mathrm{E}-17$ & $6.83 \mathrm{E}-06$ \\
\cline { 2 - 4 } $\begin{array}{c}\text { PCP } \\
\text { Downstream } \\
\text { Effector }\end{array}$ & PRICKLE4 & $3.59 \mathrm{E}-12$ & 0.006269 \\
\hline \multirow{4}{*}{\begin{tabular}{c} 
PCP Modulator \\
\cline { 2 - 4 }
\end{tabular}} & PAAM1 & 0.001307 & 0.036647 \\
\cline { 2 - 4 } & PCDH9 & $4.93 \mathrm{E}-31$ & 0.001183 \\
\cline { 2 - 4 } & PCDHA1 & $79 \mathrm{E}-09$ & $6.38 \mathrm{E}-05$ \\
\cline { 2 - 4 } & PCDHB3 & $3.65 \mathrm{E}-07$ & 0.024696 \\
\cline { 2 - 4 } & SPRY1 & 0.004801 & 0.009221 \\
\cline { 2 - 4 } & PTK7 & $1.22 \mathrm{E}-27$ & 0.018827 \\
\hline & $1.02 \mathrm{E}-13$ & 0.000889 \\
\hline
\end{tabular}

Figure 9 Knockdown of $F Z D 7$ decreases the localisation of CK1 $\varepsilon$ and DVL2 pSer143 at the centrosome. Graphs represent the percentage of cells that have (a) CK1 $\varepsilon$ and (b) DVL2 pSer143 localisation at the centrosome after FZD7 downregulation. (c) Graph shows relative TOP FLASH activity after $F Z D 7$ knockdown. $P$-value * $<0.05$, ${ }^{* *}<0.01$ and ${ }^{* * *}<0.001$. (d) Table shows the OC microarray data analysis of Wnt/PCP pathway that are enriched in the Stem-A subtype

$\beta$-catenin (BD Biosciences), p120 catenin (BD Biosciences), DVL2 pS143 (GeneTex, Irvine, CA, USA), CK1E (Santa Cruz Biotechnology Inc., Dallas, TX, USA), pan-cadherin (Abcam, Cambridge, MA, USA) and pMLC2 (Ser19) (Cell Signaling Technology, Beverly, MA, USA); 1:200 for rhodamine phalloidin F-actin (Sigma-Aldrich); and 1:1000 for $\gamma$-tubulin (Sigma-Aldrich). Alexa Fluor-488 and -594 secondary anti-mouse and anti-rabbit antibodies (Invitrogen, Eugene, OR, USA) were used at 1:1000 dilutions. Cells were mounted with Vectashield mounting medium containing DAPI (Vector Laboratories Inc., Burlingame, CA, USA).

Analysis of internuclear distance. $\mathrm{CH} 1, \mathrm{PA} 1$ and $\mathrm{OV}-17 \mathrm{R}$ cells grown, fixed and stained with DAPI on coverslips were used for the internuclear distance analysis. To measure the internuclear distance, random images of the cell colonies were captured at $\times 60$ magnification using Nikon A1R confocal microscope (Nikon Instrument Inc., Japan). The internuclear distances were measured from the centre of each nucleus to the centre of neighbouring/adjacent nucleus. The distance between the two nuclei was measured by selecting distance measure option in NIS Software (Nikon Instrument Inc.). A minimum of 200 nuclear distances were taken to obtain the mean internuclear distance for each condition.

Cell proliferation assay. Cells were seeded into wells of a 6-well plate at densities of 200000 cells per wells for $\mathrm{CH} 1$ and 100000 cells per wells for PA1 and OV-17R cell lines. Cells were then transfected with FZD7 siRNA or the negative control for $48 \mathrm{~h}$ (CH1, PA-1) or $72 \mathrm{~h}$ (OV-17R). Following transfection, cells were washed, harvested and counted using C-CHIP Haemocytometer (Digital Bio Technology, Seoul, South Korea). For MTS assay, transfected cells were incubated with CellTiter 96 AQueous Non-Radioactive Cell Proliferation Assay (Promega, Fitchburg, WI, USA) reagents for $2 \mathrm{~h}$ at $37^{\circ} \mathrm{C}$ in $5 \% \mathrm{CO}_{2}$, according to the manufacturer's protocol. An Infinite M200 plate reader (Tecan Group Ltd, Männedorf, Switzerland) was used to measure the absorbance at $490 \mathrm{~nm}$.

$\boldsymbol{\beta}$-Galactosidase assay. Knockdown of FZD7 were carried out as described above. Forty-eight hours after silencing, the fraction of cells in senescence were determined by the $\beta$-galactosidase assay (Thermo Scientific, Waltham, MA, USA) according to the manufacturer's protocol.

Wnt5a treatment. In all, 100000 cells were seeded into the wells of a 6-well plate. Recombinant Wnt5a of $200 \mathrm{ng} / \mathrm{ml}$ (R\&D Systems, Minneapolis, MN, USA) was added immediately after seeding together with the FZD7 siRNA transfection reagents as described above. After $48 \mathrm{~h}$ of transfection, phase-contrast images were taken under $\times 10$ magnification (Carl Zeiss Microscopy, Gottingen, Germany) to observe the phenotypic changes.

RhoA, Rac1 and cdc42 activation assay. For RhoA, Rac1 and cdc42 activation assays (Cytoskeleton Inc., Denver, CO, USA), cells were seeded in 6-well plates and transfected with $F Z D 7$ or negative control siRNA as described above. The experiments were then performed according to the manufacturer's protocol.

Apoptotic assay. Cells were transfected as described above and washed with PBS. Equal numbers of cells were resuspended in $100 \mu \mathrm{l}$ of Annexin binding buffer, $5 \mu \mathrm{l}$ of Pacific Blue Annexin-V (Sigma) and $1 \mu \mathrm{l}$ of $100 \mu \mathrm{g} / \mathrm{ml}$ propidium iodide (Sigma) working solution for $15 \mathrm{~min}$ at room temperature. Data were acquired using a BD LSRIl flow cytometer (BD Biosciences).

Wound healing assay. Cells were transfected with one of two different FZD7 siRNA or the negative control in 6-well plates. After transfection, the cells were harvested and counted, and 100000 cells (CH1 and PA-1) or 50000 cells 
(OV-17R) were reseeded into each spot of an Ibidi culture insert (maintained in 6 -well plates), and incubated for $12 \mathrm{~h}$. After incubation, the culture insert was removed and live imaging was performed using Nikon C1 Microscope (Nikon, Tokyo, Japan).

Luciferase assay for TopFlash activities. Cells (100 000) were seeded into the wells of a 6-well plate and transfected as described above. After $24 \mathrm{~h}$ of transfection, the medium were removed and the cells washed with PBS and replaced by $2 \mathrm{ml}$ of fresh medium. The cells were then further transfected with $1 \mu \mathrm{g}$ TopFlash and FopFlash plasmids and $10 \mathrm{ng}$ of Renilla plasmid as an internal control using Xtremegene HP (Roche) at a 1:3 ratio. After $24 \mathrm{~h}$ of incubation, the Dual-Luciferase Reporter Assay System Kit (Promega) was used according to the manufacturer's protocol. Luminescence was read using the Sirius luminometer (Berthold Detection System, Pforzheim, Germany).

Gene expression profile of FZD7 and Wnt/PCP genes in OC microarray data set. Gene expression data of 1538 OC tumours and 142 $\mathrm{OC}$ cell lines, and the assignments of $\mathrm{OC}$ molecular subtype were as described previously. ${ }^{4}$ Gene expression of FZD7 and Wnt/PCP genes for Epi-A, Epi-B, Mes, Stem-A and Stem-B were extracted and compared. Binary Mann-Whitney test comparing among the various subtypes was used to assess for significant differences in gene expression.

\section{Conflict of Interest}

The authors declare no conflict of interest.

Acknowledgements. We thank Dr. R Jackson for her careful English editing We are grateful for the financial support from Cancer Science Institute of Singapore National Medical Research Council (NMRC) New Investigator Grant (NIG) (NMRC/ $\mathrm{NIG} / 1040 / 2011$ ) and National University Cancer Institute of Singapore (NCIS) Centre Grant Pilot Program FY2012 (NMRC/CG/NCIS/2012).

1. Tothill RW, Tinker AV, George J, Brown R, Fox SB, Lade S et al. Novel molecular subtypes of serous and endometrioid ovarian cancer linked to clinical outcome. Clin Cancer Res 2008; 14: 5198-5208.

2. TCGA (Cancer Genome Atlas Research Network). Integrated genomic analyses of ovarian carcinoma. Nature 2011; 474: 609-615.

3. Tan TZ, Miow QH, Huang RY, Wong MK, Ye J, Lau JA et al. Functional genomics identifies five distinct molecular subtypes with clinical relevance and pathways for growth control in epithelial ovarian cancer. EMBO Mol Med 2013; 5: 983-998.

4. Palacios J, Gamallo C. Mutations in the beta-catenin gene (CTNNB1) in endometrioid ovarian carcinomas. Cancer Res 1998; 58: 1344-1347.

5. Kildal W, Risberg B, Abeler VM, Kristensen GB, Sudbø J, Nesland JM et al. Beta-catenin expression, DNA ploidy and clinicopathological features in ovarian cancer: a study in 253 patients. Eur J Cancer 2005; 41: 1127-1134.

6. Veeman MT, Axelrod JD, Moon RT. A second canon. Functions and mechanisms of betacatenin-independent Wnt signaling. Dev Cell 2003; 5: 367-377.

7. Reya T, Clevers H. Wnt signalling in stem cells and cancer. Nature 2005; 434: 843-850.

8. Reya T, Duncan A, Ailles L, Domen J, Scherer DC, Willert K et al. A role for Wnt signalling in self-renewal of haematopoietic stem cells. Nature 2003; 423: 409-414.

9. Yu Q, Liu L, Duan Y, Wang Y, Xuan X, Zhou L et al. Wnt/beta-catenin signaling regulates neuronal differentiation of mesenchymal stem cells. Biochem Biophys Res Commun 2013; 439: 297-302.

10. Wang Q, Symes AJ, Kane CA, Freeman A, Nariculam J, Munson P et al. A novel role fo $\mathrm{Wnt} / \mathrm{Ca}^{2+}$ signaling in actin cytoskeleton remodeling and cell motility in prostate cancer PLoS One 2010; 5: e10456.

11. Dissanayake SK, Wade M, Johnson CE, O'Connell MP, Leotlela PD, French AD et al. The Wnt5A/protein kinase $C$ pathway mediates motility in melanoma cells via the inhibition of metastasis suppressors and initiation of an epithelial to mesenchymal transition. $J$ Biol Chem 2007; 282: 17259-17271.

12. Nobes $\mathrm{CD}$, Hall A. Rho GTPases control polarity, protrusion, and adhesion during cell movement. J Cell Biol 1999; 144: 1235-1244.

13. Raftopoulou M, Hall A. Cell migration: Rho GTPases lead the way. Dev Biol 2004; 265 23-32.

14. Katoh M. WNT/PCP signaling pathway and human cancer [review]. Oncol Rep. 2005; 14 1583-1588

15. Ridley AJ. Rho proteins and cancer. Breast Cancer Res Treat 2004; 84: 13-19.

16. Zhang Z, Rankin SA, Zorn AM. Different thresholds of Wnt-Frizzled 7 signaling coordinate proliferation, morphogenesis and fate of endoderm progenitor cells. Dev Biol 2013; 378: $1-12$.
17. Abu-Elmagd M, Garcia-Morales C, Wheeler GN. Frizzled7 mediates canonical Wnt signaling in neural crest induction. Dev Biol 2006; 298: 285-298.

18. Yang L, Wu X, Wang Y, Zhang K, Wu J, Yuan Y et al. FZD7 has a critical role in cell proliferation in triple negative breast cancer. Oncogene 2011; 30: 4437-4446.

19. Ueno K, Hazama S, Mitomori S, Nishioka M, Suehiro Y, Hirata H et al. Down-regulation of frizzled-7 expression decreases survival, invasion and metastatic capabilities of colon cancer cells. Br J Cancer 2009; 101: 1374-1381.

20. Merle P, Kim M, Herrmann M, Gupte A, Lefrançois L, Califano S et al. Oncogenic role of the frizzled-7/beta-catenin pathway in hepatocellular carcinoma. J Hepatol 2005; 43: 854-862.

21. Kaucká M, Plevová K, Pavlová S, Janovská P, Mishra A, Verner J et al. The planar cell polarity pathway drives pathogenesis of chronic lymphocytic leukemia by the regulation of B-lymphocyte migration. Cancer Res 2013; 73: 1491-1501.

22. Huang RY, Wong MK, Tan TZ, Kuay KT, Ng AH, Chung VY et al. An EMT spectrum defines an anoikis-resistant and spheroidogenic intermediate mesenchymal state that is sensitive to e-cadherin restoration by a src-kinase inhibitor, saracatinib (AZD0530). Cell Death Dis 2013; 4: e915.

23. Klein T, Jenny A, Diiane A, Mlodzik M. CKlepsilon/discs overgrown promotes both Wnt-Fz beta-catenin and Fz/PCP signaling in Drosophila. Curr Biol 2006; 16: 1337-1343.

24. Lee KH, Johmura Y, Yu LR, Park JE, Gao Y, Bang JK et al. Identification of a nove Wnt5a-CK1 1 -Dvl2-Plk1-mediated primary cilia disassembly pathway. EMBO J 2012; 31: 3104-3117.

25. Wang Y. Wnt/Planar cell polarity signaling: a new paradigm for cancer therapy. Mol Cancer Ther 2009; 8: 2103-2109.

26. Tanaka S, Akiyoshi T, Mori M, Wands JR, Sugimachi K. A novel frizzled gene identified in human esophageal carcinoma mediates APC/beta-catenin signals. Proc Natl Acad Sci USA 1998; 95: 10164-10169.

27. Kirikoshi $\mathrm{H}$, Sekihara $\mathrm{H}$, Katoh M. Up-regulation of Frizzled-7 (FZD7) in human gastric cancer. Int J Oncol 2001; 19: 111-115.

28. Kim M, Lee HC, Tsedensodnom O, Hartley R, Lim YS, Yu E et al. Functional interaction between Wnt3 and Frizzled-7 leads to activation of the Wnt/beta-catenin signaling pathway in hepatocellular carcinoma cells. J Hepatol 2008; 48: 780-791.

29. Merle P, de la Monte S, Kim M, Herrmann M, Tanaka S, Von Dem Bussche A et al. Functional consequences of frizzled-7 receptor overexpression in human hepatocellular carcinoma. Gastroenterology 2004; 127: 1110-1122.

30. Vincan E, Darcy PK, Smyth MJ, Thompson EW, Thomas RJ, Phillips WA et al. Frizzled-7 receptor ectodomain expression in a colon cancer cell line induces morphological change and attenuates tumor growth. Differentiation 2005; 73: 142-153.

31. Vincan E, Flanagan DJ, Pouliot N, Brabletz T, Spaderna S. Variable FZD7 expression in colorectal cancers indicates regulation by the tumour microenvironment. Dev Dyn 2010; 239: 311-317.

32. Melchior K, Weiss J, Zaehres H, Kim YM, Lutzko C, Roosta N et al. The WNT recepto FZD7 contributes to self-renewal signaling of human embryonic stem cells. Biol Chem 2008; 389: 897-903.

33. Fernandez A, Huggins IJ, Perna L, Brafman D, Lu D, Yao S et al. The WNT receptor FZD7 is required for maintenance of the pluripotent state in human embryonic stem cells. Proc Natl Acad Sci USA 2014; 111: 1409-1414.

34. Assou S, Le Carrour T, Tondeur S, Ström S, Gabelle A, Marty S et al. A meta-analysis of human embryonic stem cells transcriptome integrated into a web-based expression atlas. Stem Cells 2007; 25: 961-973.

35. Dormeyer W, van Hoof D, Braam SR, Heck AJ, Mummery CL, Krijgsveld J. Plasma membrane proteomics of human embryonic stem cells and human embryonal carcinoma cells. J Proteome Res 2008; 7: 2936-2951.

36. Vijayaragavan K, Szabo E, Bossé M, Ramos-Mejia V, Moon RT, Bhatia M. Noncanonical Wnt signaling orchestrates early developmental events toward hematopoietic cell fate from human embryonic stem cells. Cell Stem Cell 2009; 4: 248-262.

37. Le Grand F, Jones AE, Seale V, Scimè A, Rudnicki MA. Wnt7a activates the planar cell polarity pathway to drive the symmetric expansion of satellite stem cells. Cell Stem Cell 2009; 4: 535-547.

38. Pillé JY, Denoyelle C, Varet J, Bertrand JR, Soria J, Opolon P et al. Anti-RhoA and antiRhoC siRNAs inhibit the proliferation and invasiveness of MDA-MB-231 breast cancer cells in vitro and in vivo. Mol Ther 2005; 11: 267-274.

39. Zhang S, Tang Q, Xu F, Xue Y, Zhen Z, Deng Y et al. RhoA regulates G1-S progression of gastric cancer cells by modulation of multiple INK4 family tumor suppressors. Mol Cancer Res 2009; 7: 570-580.

40. Vincan E, Darcy PK, Farrelly CA, Faux MC, Brabletz T, Ramsay RG. Frizzled-7 dictates three-dimensional organization of colorectal cancer cell carcinoids. Oncogene 2007; 26: 2340-2352.

41. Sander EE, ten Klooster JP, van Delft $S$, van der Kammen RA, Collard JG. Rac downregulates Rho activity: reciprocal balance between both GTPases determines cellular morphology and migratory behavior. J Cell Biol 1999; 147: 1009-1022.

42. Takaishi K, Sasaki T, Kotani H, Nishioka H, Takai Y. Regulation of cell-cell adhesion by rac and rho small G proteins in MDCK cells. J Cell Biol 1997; 139: 1047-1059.

43. Guo X, Wang M, Jiang J, Xie C, Peng F, Li X et al. Balanced Tiam1-rac1 and RhoA drives proliferation and invasion of pancreatic cancer cells. Mol Cancer Res 2013; 11: 230-239.

44. Kurayoshi M, Oue N, Yamamoto H, Kishida M, Inoue A, Asahara T et al. Expression of Wnt-5a is correlated with aggressiveness of gastric cancer by stimulating cell migration and invasion. Cancer Res 2006; 66: 10439-10448. 
45. Pukrop T, Klemm F, Hagemann T, Gradl D, Schulz M, Siemes S et al. Wnt 5a signaling is critical for macrophage-induced invasion of breast cancer cell lines. Proc Natl Acad Sci USA 2006; 103: 5454-5459.

46. Weeraratna AT, Jiang $Y$, Hostetter G, Rosenblatt $K$, Duray $P$, Bittner $M$ et al. Wnt5a signaling directly affects cell motility and invasion of metastatic melanoma. Cancer Cell. 2002; 1: 279-288.

47. Amano M, Ito M, Kimura K, Fukata $Y$, Chihara K, Nakano T et al. Phosphorylation and activation of myosin by Rho-associated kinase (Rho-kinase). J Biol Chem 1996; 271: 20246-20249.

48. Hidalgo-Carcedo C, Hooper S, Chaudhry SI, Williamson P, Harrington K, Leitinger B et al. Collective cell migration requires suppression of actomyosin at cell-cell contacts mediated by DDR1 and the cell polarity regulators Par3 and Par6. Nat Cell Biol. 2011; 13: 49-58.

49. Kraft B, Berger C, Wallkamm V, Steinbeisser H, Wedlich D. Wnt-11 and Fz7 reduce cell adhesion in convergent extension by sequestration of PAPC and C-cadherin. $J$ Cell Biol 2012; 198: 695-709.

50. Brieher WM, Yap AS, Gumbiner BM. Lateral dimerization is required for the homophilic binding activity of C-cadherin. J Cell Biol 1996; 135: 487-496.

51. Yap AS, Brieher WM, Pruschy M, Gumbiner BM. Lateral clustering of the adhesive ectodomain: a fundamental determinant of cadherin function. Curr Biol 1997; 7: 308-315.

52. Troyanovsky SM. Regulation of cadherin-based epithelial cell adhesion by endocytosis. Front Biosci (Schol Ed) 2009; 1: 61-67.

53. Kam Y, Quaranta V. Cadherin-bound beta-catenin feeds into the Wnt pathway upon adherens junctions dissociation: evidence for an intersection between beta-catenin pools. PLoS One 2009; 4: e4580.

54. Peters JM, McKay RM, McKay JP, Graff JM. Casein kinase I transduces Wnt signals. Nature 1999; 401: 345-350.

55. Amit S, Hatzubai A, Birman Y, Andersen JS, Ben-Shushan E, Mann M et al. Axin-mediated CKI phosphorylation of beta-catenin at Ser 45: a molecular switch for the Wnt pathway. Genes Dev 2002; 16: 1066-1076.
56. Foldynová-Trantírková S, Sekyrová P, Tmejová K, Brumovská E, Bernatík O, Blankenfeld W et al. Breast cancer-specific mutations in CK1 epsilon inhibit Wnt/beta-catenin and activate the Wnt/Rac1/JNK and NFAT pathways to decrease cell adhesion and promote cell migration. Breast Cancer Res 2010; 12: R30.

57. Cong F, Schweizer L, Varmus $H$. Casein kinase lepsilon modulates the signaling specificities of dishevelled. Mol Cell Biol 2004; 24: 2000-2011.

58. Rodriguez N, Yang J, Hasselblatt K, Liu S, Zhou Y, Rauh-Hain JA et al. Casein kinase I epsilon interacts with mitochondrial proteins for the growth and survival of human ovarian cancer cells. EMBO Mol Med 2012; 4: 952-963.

59. Fujii N, You L, Xu Z, Uematsu K, Shan J, He B et al. An antagonist of dishevelled proteinprotein interaction suppresses beta-catenin-dependent tumor cell growth. Cancer Res 2007; 67: 573-579.

60. Pode-Shakked N, Harari-Steinberg O, Haberman-Ziv Y, Rom-Gross E, Bahar S, Omer D et al. Resistance or sensitivity of Wilms' tumor to anti-FZD7 antibody highlights the Wnt pathway as a possible therapeutic target. Oncogene 2011; 30: 1664-1680.

(i) $(9)$ Cell Death and Disease is an open-access journal published by Nature Publishing Group. This work is licensed under a Creative Commons Attribution-NonCommercialNoDerivs 3.0 Unported License. The images or other third party material in this article are included in the article's Creative Commons license, unless indicated otherwise in the credit line; if the material is not included under the Creative Commons license, users will need to obtain permission from the license holder to reproduce the material. To view a copy of this license, visit http://creativecommons.org/ licenses/by-nc-nd/3.0/

Supplementary Information accompanies this paper on Cell Death and Disease website (http://www.nature.com/cddis) 